\title{
Evaluation of Recruited Lung Volume at Inspiratory Plateau Pressure With PEEP Using Bedside Digital Chest X-ray in Patients With Acute Lung Injury/ARDS
}

\author{
Florent Wallet MD, Bertrand Delannoy MD, Audrey Haquin MD, Sophie Debord MD, \\ Véronique Leray MD, Gaël Bourdin MD, Frédérique Bayle MD, \\ Jean-Christophe Richard MD PhD, Loic Boussel MD PhD, and Claude Guérin MD PhD
}

\begin{abstract}
BACKGROUND: We wanted to assess whether there was a significant relationship between recruited lung volume $\left(\mathrm{V}_{\text {rec }}\right)$ and change in density on digital processed chest $\mathrm{x}$-ray measured at 2 different levels of inspiratory plateau pressure corresponding to 2 PEEP levels in patients with acute lung injury or ARDS. METHODS: In 14 subjects, PEEP $5 \mathrm{~cm} \mathrm{H}_{2} \mathrm{O}$ and $15 \mathrm{~cm} \mathrm{H}_{2} \mathrm{O}$ were prospectively applied in a random order for $10 \mathrm{~min}$. At the end of each period, chest $\mathrm{x}$-ray was taken using a digital portable device, and a pressure-volume curve of the respiratory system was performed. We also assessed $\mathrm{P}_{\mathrm{aO}}$, and the static and the dynamic $\left(\mathrm{C}_{\mathrm{dyn}, \mathrm{rs}}\right)$ compliance of the respiratory system. Change in end-expiratory lung volume between tidal breath and relaxation volume of the respiratory system was determined. Radiological attenuation was measured on chest $\mathrm{x}$-rays in 4 regions of interest in the right lung, and in 3 regions of interest in the left lung, drawn in posterior intercostal spaces from top to bottom, by using dedicated software. The ratio of lung density in each region between PEEP 15 and PEEP 5 (rP15/P5) and their arithmetic mean ( $\mu$ P15/P5) were computed. $V_{\text {rec }}$ was determined from the pressure-volume curves. RESULTS: The median value of rP15/P5 in the 98 lung levels was $0.91(0.80-1.01)$, which was significantly different from $1(P<.001)$. The values of $\mathrm{rP15} / \mathrm{P5}$ were not significantly different between the lung levels. The median values of $V_{\text {rec }}$ and $\mu \mathrm{P} 15 / \mathrm{P} 5$ were $288(173-402) \mathrm{mL}$ and $0.90(0.80-0.97)$, respectively. There was a significant negative correlation between $\mathrm{V}_{\text {rec }}$ and $\mu \mathrm{P} 15 / \mathrm{P5}(\mathrm{R}=-0.77, P=.01)$. The reduction in $\mu \mathrm{P} 15 / \mathrm{P5}$ tended to correlate with the increase in $\mathrm{C}_{\mathrm{dyn}, \mathrm{rs}}(\mathrm{R}=-\mathbf{0 . 4 9 , P}=.077)$ or in $\mathrm{P}_{\mathrm{aO}}(\mathrm{R}=-0.53$, $P=.05)$ between PEEP $15 \mathrm{~cm} \mathrm{H}_{2} \mathrm{O}$ and PEEP $5 \mathrm{~cm} \mathrm{H}_{2} \mathrm{O}$. CONCLUSIONS: Digital chest $\mathrm{x}$-ray done at the bedside in acute lung injury/ARDS subjects was able to detect a reduction in density between PEEP $5 \mathrm{~cm} \mathrm{H}_{2} \mathrm{O}$ and PEEP $15 \mathrm{~cm} \mathrm{H_{2 }} \mathbf{O}$, which correlated with $\mathbf{V}_{\text {rec }}$. Key Words: ALI; ARDS; pressure-volume curve; lung recruitment; PEEP; lung density; chest $x$-ray. [Respir Care 2013;58(3): 416-423. (c) 2013 Daedalus Enterprises]
\end{abstract}

\section{Introduction}

The main goal of mechanical ventilation in patients with acute lung injury (ALI) or ARDS is to prevent lung over- distention and to maintain lung recruitment. PEEP is an expiratory setting that induces an increase in end-expiratory lung volume. As such, PEEP may avoid the repeated

\footnotetext{
The authors have disclosed no conflicts of interest.
}

Correspondence: Claude Guérin MD PhD, Service de Réanimation Médicale, Hôpital de la Croix Rousse, 103 Grande Rue de la Croix Rousse, 69004 Lyon, France. E-mail: claude.guerin@chu-lyon.fr.

DOI: $10.4187 /$ respcare. 01893 
opening and closing of the small airways and maintain tidal lung recruitment. However, there is no definite evidence that PEEP level can impact patient survival. ${ }^{1-4}$ Therefore, one should consider titrating PEEP from the patient's individual physiological characteristics. One possible approach is to select PEEP by assessing alveolar recruitment. However, this requires the performance of a computed lung tomography (CT). ${ }^{5}$ This approach is limited by the risk of patient transportation outside of the ICU and timeconsuming data analysis, the results of which cannot be obtained as quickly as optimal patient care requires. Bedside methods are, therefore, a very attractive alternative, and pressure-volume curve construction is easy to perform with virtually all modern ICU ventilators. Nowadays certain lung imaging techniques, such as lung ultrasonography or electrical impedance tomography, can be performed at the bedside and may help the clinician to monitor lung recruitment ${ }^{6,7}$ and titrate mechanical ventilation. ${ }^{8}$ However, these techniques require specific and costly equipment and are time-consuming. Chest $\mathrm{x}$-ray is routinely and easily performed at the bedside, ${ }^{9}$ and the digitalization process makes quantitative examinations of the lungs possible and readily available. We therefore asked whether or not the measurement of lung density from the digital processed chest $\mathrm{x}$-ray might be useful for the bedside assessment of lung recruitment.

\section{See the Related Editorial on Page 539}

The present study addresses the following question: Is there a significant relationship between recruited lung volume $\left(\mathrm{V}_{\text {rec }}\right)$ measured at end-inspiration and change in density on the digital processed chest x-ray at different PEEP in ALI/ARDS patients? Our hypothesis was that increasing plateau pressure with PEEP would result in a decrease in lung density that correlated with the increase in $\mathrm{V}_{\text {rec}}$.

\section{Methods}

This work was endorsed by the Hospices Civils de Lyon (reference 2006.423/16; registration number 2008A00071-54).

\section{Subjects}

The protocol was approved by the local ethics committee on April 10, 2008 (Comité de Protection des Personnes Sud-Est IV). Patients were included if they met all the following inclusion criteria:

\section{QUICK LOOK}

\section{Current knowledge}

An evidenced-based approach to mechanical ventilation in ARDS requires lung-protective ventilation with small tidal volumes $(6 \mathrm{~mL} / \mathrm{kg})$. The role of PEEP in lung protection is less defined, and the impact of PEEP on mortality is controversial. The optimum PEEP setting that provides alveolar recruitment but prevents overdistension remains elusive and is best determined on a case by case basis.

\section{What this paper contributes to our knowledge}

Bedside digital chest radiography can detect changes in lung density, which are correlated with lung recruitment associated with a change in PEEP of $10 \mathrm{~cm} \mathrm{H}_{2} \mathrm{O}$. Compared to other methods of detecting recruitment, bedside digital chest radiography is readily available and does not require patient transport. The clinical usefulness remains to be evaluated in a clinical trial.

- ALI/ARDS defined according to the consensus conference criteria $^{10}$ at $\mathrm{PEEP} \geq 5 \mathrm{~cm} \mathrm{H}_{2} \mathrm{O}$

- Age $\geq 18$ years

- Intubation and mechanical ventilation in the ICU

- Continuous intravenous sedation and analgesia, with a Ramsay score of 6

- Ongoing mechanical ventilation delivered by an ICU ventilator, implemented to perform a low inflation flow pressure-volume curve

- No pneumothorax on the chest x-ray

- Pleural fluid effusion $<500 \mathrm{~mL}$, as estimated from lung ultrasonography

- Written informed consent obtained from the next of kin Patients were excluded if any of the following exclusion criteria was present:

- Thoracic surgery in the last 3 months

- Recent history of pneumonectomy or lobectomy

- Pregnancy

- Subject under guardianship

- Refusal to participate from the next of kin

\section{Measurements Setup}

Pressure at the airway opening was measured at the proximal end of the endotracheal tube, and air flow was 
Table. Respiratory Mechanics and Oxygenation in 14 ARDS Patients

\begin{tabular}{|c|c|c|c|c|c|c|}
\hline PEEP & $\begin{array}{c}\mathrm{P}_{\text {plat,rs }} \\
\mathrm{cm} \mathrm{H} \mathrm{H}_{2} \mathrm{O}\end{array}$ & $\begin{array}{l}\mathrm{PEEP}_{\mathrm{t}, \mathrm{rs}} \\
\mathrm{cm} \mathrm{H} \mathrm{H}_{2} \mathrm{O}\end{array}$ & $\begin{array}{c}\mathrm{C}_{\mathrm{st}, \mathrm{rs}} \\
\mathrm{mL} / \mathrm{cm} \mathrm{H}_{2} \mathrm{O}\end{array}$ & $\begin{array}{c}\mathrm{C}_{\text {dyn,rs }} \\
\mathrm{mL} / \mathrm{cm} \mathrm{H}_{2} \mathrm{O}\end{array}$ & $\begin{array}{c}\mathrm{P}_{\mathrm{aO}} / \mathrm{F}_{\mathrm{IO}_{2}} \\
\mathrm{~mm} \mathrm{Hg}\end{array}$ & $\begin{array}{c}\mathrm{P}_{\mathrm{aO}_{2}} \\
\mathrm{~mm} \mathrm{Hg}\end{array}$ \\
\hline $5 \mathrm{~cm} \mathrm{H}_{2} \mathrm{O}$ & $16(14-17)$ & $6(6-8)$ & $44(31-55)$ & $32(26-39)$ & 157 (139-183) & 77 (66-91) \\
\hline $15 \mathrm{~cm} \mathrm{H}_{2} \mathrm{O}$ & $27 \dagger(25-30)$ & $16 \dagger(16-16)$ & $31(26-50)$ & $29(20-40)$ & $182 *(136-272)$ & $79 *(70-133)$ \\
\hline \multicolumn{7}{|c|}{ 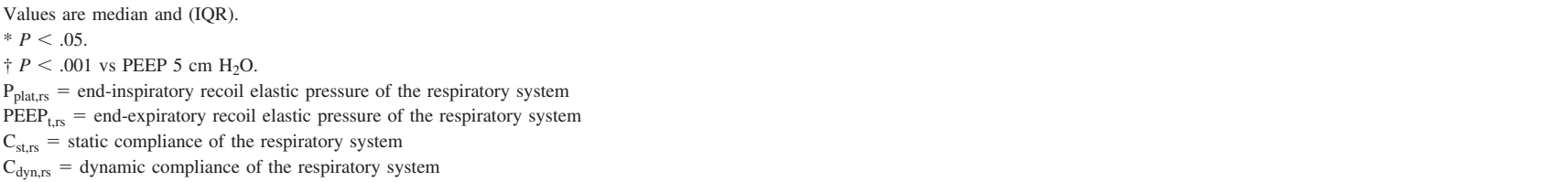 } \\
\hline
\end{tabular}

measured using a pneumotachograph inserted between the port for the airway opening pressure (VBM Medizintechnik, Sulz am Neckar, Germany) and the Y-piece of the ventilator circuit. Analog signals were sampled at $200 \mathrm{~Hz}$ (AcqKnowledge 3.8.5, Biopac Systems, Goleta, California) and sent to an analog-to-digital card (MP150, Biopac Systems, Goleta, California). The records were stored on the computer for further analysis. Change in lung volume was obtained by numerical integration of the flow signal.

Chest $\mathrm{x}$-rays were performed at the bedside using a digital mobile X-ray system (Mobilett Plus, Siemens, Berlin, Germany) designed by the investigators (FW, BD, $\mathrm{CG})$. The exposure parameters (kilovolts and milliampereseconds) were set according to standard values and adjusted depending on the subject's weight. A distance of $1 \mathrm{~m}$ between the source of the electron beam and the plane of the subject's thorax was selected, and the collimator angulation was correctly adjusted using the device's light markers. These parameters were left unchanged and the chest $\mathrm{x}$-ray system kept in the same place in the room throughout the study.

\section{Measurements}

The measurements were performed in the following order at each PEEP level. First, $2 \mathrm{~mL}$ of blood was sampled from the arterial line and sent immediately to the laboratory for blood gas assessment (ABL 725, Radiometer, Brønshøj, Denmark). Second, a 3 second end-expiratory occlusion, followed by a 5-second end-inspiratory occlusion was performed by pressing the appropriate baseline settings on the ventilator (Table). Third, at the end of the inspiratory pause a chest $\mathrm{x}$-ray was taken. Then 10 baseline cycles were allowed for stabilization, and slow inflation at constant flow was performed using the built-in software that works as follows: From the current PEEP level at the end of expiration, constant inflation flow of $7 \mathrm{~L} / \mathrm{min}$ was delivered from the ventilator until maximal inspiratory airway opening pressure of $35 \mathrm{~cm} \mathrm{H}_{2} \mathrm{O}$ or maximal inspiratory volume of $1 \mathrm{~L}$ was reached (first criterion passed). The same level of PEEP was recovered at the end of the following expiration. Finally, after baseline ventilation had been resumed for 10 consecutive breaths, the subject was disconnected from the ventilator at the Ypiece to freely exhale to the relaxation volume of the respiratory system. The subject was then reconnected to the ventilator.

\section{Protocol}

All subjects were included after the investigators had obtained the written informed consent, read and signed by the next of kin. Subjects included were ventilated (Evita XL, Dräger, Lübeck, Germany) in volume-controlled mode at constant inflation flow. They were kept in a $15-20^{\circ}$ recumbent supine position throughout the study procedure. Once the subject had met the inclusion and exclusion criteria, the adequacy of sedation was checked. Neuromuscular blockade $(0.15 \mathrm{mg} / \mathrm{kg}$ actual body weight besylate cisatracurium) was used if inspiratory efforts were present or plateau pressure was $>30 \mathrm{~cm} \mathrm{H}_{2} \mathrm{O}$ despite a Ramsay score of 6 . Then the measurement setup was installed and an X-ray cassette placed behind the subject to perform the anterior-posterior chest $\mathrm{x}$-ray. Care was taken to remove any foreign bodies from the torso area, such as electrocardiogram electrodes, nasogastric tubes, or equipment, from the field of view of the chest $\mathrm{x}$-ray images. Subjects were allocated to receive 5 and $15 \mathrm{~cm} \mathrm{H}_{2} \mathrm{O}$ PEEP levels, in a random order, each applied for $10 \mathrm{~min}$. At the end of each PEEP level the measurements were performed in the order described above. Then, the $\mathrm{x}$-ray cassette was removed and another one inserted for the next PEEP level. At the end of the protocol the measurement setup was removed. The baseline ventilator settings were kept unchanged during the study, except for $\mathrm{F}_{\mathrm{IO}_{2}}$ and tidal volume, which were adjusted to obtain $\mathrm{S}_{\mathrm{pO}_{2}} \geq 88 \%$ and plateau pressure $\leq 30 \mathrm{~cm} \mathrm{H}_{2} \mathrm{O}$, respectively.

During the study an investigator was always present to provide for patient care. Heart rate, $\mathrm{S}_{\mathrm{pO}_{2}}$, and arterial blood pressure were continuously monitored (IntelliVue MP90, 
Philips Healthcare, Best, Netherlands), as were airway pressure and flow signals at the ventilator.

The protocol was stopped if $\mathrm{S}_{\mathrm{pO}_{2}}$ was below $85 \%$ under $\mathrm{F}_{\mathrm{IO}_{2}}$ of 1.0 or when mean arterial pressure was lower than $60 \mathrm{~mm} \mathrm{Hg}$ for at least $5 \mathrm{~min}$.

\section{Data Analysis}

Respiratory Mechanics. The change in end-expiratory lung volume between tidal expiration and relaxation volume was measured at each level of PEEP. The $\mathrm{V}_{\text {rec }}$ elicited by a change of $10 \mathrm{~cm} \mathrm{H}_{2} \mathrm{O}$ above PEEP of $5 \mathrm{~cm} \mathrm{H}_{2} \mathrm{O}$ was assessed from the pressure-volume curves, as previously described. ${ }^{11}$ The pressure-volume curves at each PEEP level were superimposed on the same volume axis with the relaxation volume taken as the reference. $V_{\text {rec }}$ was defined as the difference in lung volume between PEEP of $15 \mathrm{~cm} \mathrm{H}_{2} \mathrm{O}$ and PEEP of $5 \mathrm{~cm} \mathrm{H}_{2} \mathrm{O}$ at the same pressure of $20 \mathrm{~cm} \mathrm{H}_{2} \mathrm{O}$. The end-expiratory $\left(\mathrm{PEEP}_{\mathrm{t}, \mathrm{rs}}\right)$ and endinspiratory recoil elastic pressures $\left(\mathrm{P}_{\text {plat,rs }}\right)$ of the respiratory system were measured at the baseline ventilator settings. Static compliance of the respiratory system $\left(\mathrm{C}_{\mathrm{st}, \mathrm{rs}}\right)$ was computed as tidal volume/( $\left.\mathrm{P}_{\text {plat,rs }}-\mathrm{PEEP}_{\mathrm{t}, \mathrm{rs}}\right)$. Dynamic compliance of the respiratory system $\left(\mathrm{C}_{\mathrm{dyn}, \mathrm{rs}}\right)$ was computed as the ratio between tidal volume and the difference in end-inspiratory to end-expiratory pressures at first zero flow.

Chest X-ray. The chest X-ray was processed as follows. Images were reviewed using dedicated software (DicomWorks, http://www.dicomworks.com $)^{12}$ by an experienced radiologist (AH) who was blinded to the PEEP level at which the chest X-ray was taken. For all subjects, the regions of interest were manually drawn in 3 different posterior intercostal spaces (K4-K5, K6-K7, K8-K9), from top to bottom, in both lungs. Furthermore, a fourth region of interest was drawn for the right lung only, at the posterior intercostal space K10-K11 (Fig. 1). The same strategy was applied at each PEEP level. We used polygonal, instead of circular, regions of interest, in order to fit the shape of the intercostal space. Indeed, we wanted to exclude the ribs from our measurements while maintaining a large enough area of measurement. The mean value of the density was measured in each region of interest by the software. ${ }^{12}$ Each chest $\mathrm{x}$-ray specimen was read twice by the same radiologist. In every subject, the ratio of lung density measured at the $\mathrm{P}_{\text {plat,rs }}$ corresponding to PEEP $15 \mathrm{~cm} \mathrm{H}_{2} \mathrm{O}$, to that measured at the $\mathrm{P}_{\text {plat,rs }}$ corresponding to PEEP $5 \mathrm{~cm} \mathrm{H}_{2} \mathrm{O}$, was computed for each corresponding region of interest (rP15/P5). For example, the density measured in the right $\mathrm{K} 4-\mathrm{K} 5$ intercostal space at the $\mathrm{P}_{\text {plat,rs }}$ corresponding to PEEP $15 \mathrm{~cm} \mathrm{H}_{2} \mathrm{O}$, was divided by the density measured in the same right K4-K5 intercostal space at the $\mathrm{P}_{\text {plat,rs }}$ corresponding to PEEP

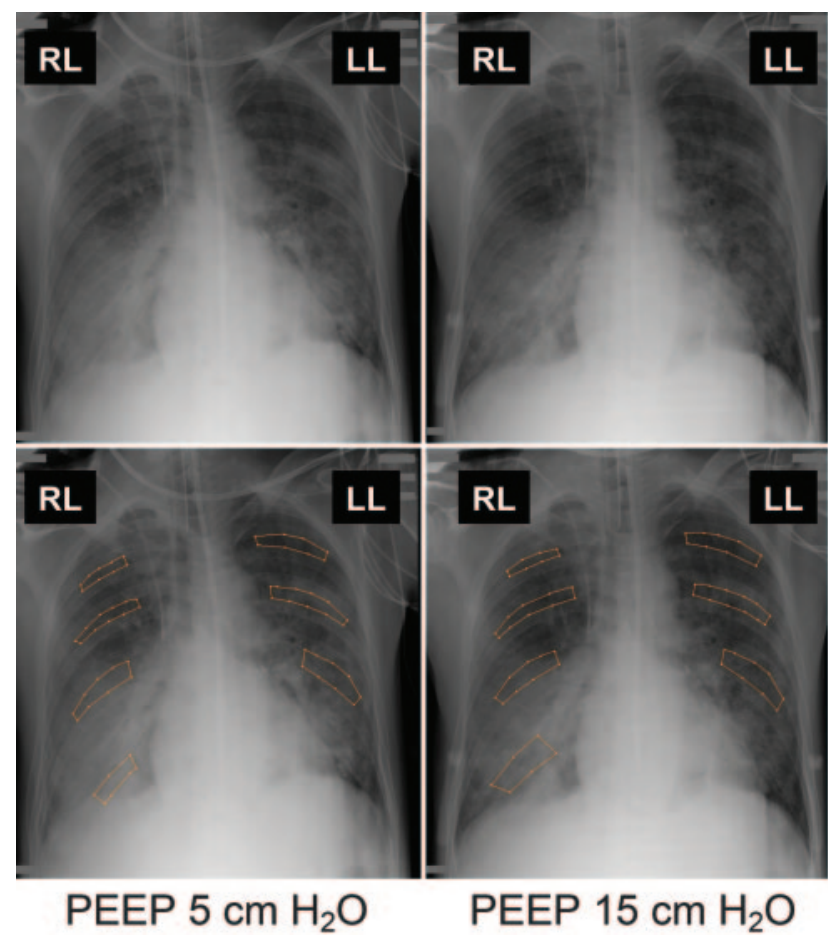

Fig. 1. Method of drawing the regions of interest to measure the lung density on a bedside digitized chest $\mathrm{x}$-ray in a representative subject in the present study. The initial images (upper panels) and the corresponding contoured images (lower panels) were obtained at PEEP of $5 \mathrm{~cm} \mathrm{H}_{2} \mathrm{O}$ (left panels) and $15 \mathrm{~cm} \mathrm{H}_{2} \mathrm{O}$ (right panels), respectively. Four regions of interest were manually drawn on the right lung, and 3 regions of interest on the left lung for each PEEP condition. The arithmetic mean of the density measured in the 7 regions of interest at PEEP $15 \mathrm{~cm} \mathrm{H}_{2} \mathrm{O}$ divided by that obtained at PEEP $5 \mathrm{~cm} \mathrm{H}_{2} \mathrm{O}$ was 0.89 in this case. $\mathrm{RR}=$ right lung. $\mathrm{LL}=$ left lung.

$5 \mathrm{~cm} \mathrm{H}_{2} \mathrm{O}$. So for every subject we obtained 7 values for $\mathrm{rP} 15 / \mathrm{P} 5$. We used this ratio to minimize the limitation due to the lack of calibration in density measurement. The 7 rP15/P5 values in every subject were summarized into their arithmetic mean $(\mu \mathrm{P} 15 / \mathrm{P} 5)$ per subject. A rP15/P5 ratio lower than 1 in the right $\mathrm{K} 4-\mathrm{K} 5$ intercostal space, as an example, indicates a reduction in lung density with the $\mathrm{P}_{\text {plat,rs }}$ corresponding to the highest PEEP in that region of interest. A $\mu \mathrm{P} 15 / \mathrm{P} 5$ ratio lower than 1 in a given subject indicates an overall reduction in lung density with the $\mathrm{P}_{\text {plat,rs }}$ corresponding to the highest PEEP in that subject. A ratio equal to 1 , whether it pertains to $\mathrm{rP} 15 / \mathrm{P} 5$ or to $\mu \mathrm{P} 15 / \mathrm{P} 5$, means no change in lung density with the $\mathrm{P}_{\text {plat,rs }}$ corresponding to the highest PEEP.

\section{Statistical Analysis}

The normal distribution of continuous variables was checked by the Shapiro-Wilk test. Continuous variables are expressed as median (IQR) unless otherwise stated. 
Intra-reader reproducibility was evaluated on all measurements. The measurement error was calculated ${ }^{13}$ as:

$100 \times \sqrt[V]{ }($ within-subject variance $) /$ mean of overall measurements

To determine the level of intra-reader agreement between 2 repeated measurements, the intra-class correlation coefficient, with its $95 \% \mathrm{CI}$, was also calculated. The average of the 2 values of rP15/P5 at each level for each lung was used in the subsequent analyses.

The primary end point was the relationship between $\mu \mathrm{P} 15 / \mathrm{P} 5$ and $\mathrm{V}_{\text {rec }}$. The secondary end points were the relationships between $\mu \mathrm{P} 15 / \mathrm{P} 5$ and change in $\mathrm{P}_{\mathrm{aO}}, \mathrm{C}_{\text {st.rs }}$, and $\mathrm{C}_{\mathrm{dyn}, \mathrm{rs}}$ between PEEP $15 \mathrm{~cm} \mathrm{H}_{2} \mathrm{O}$ and PEEP $5 \mathrm{~cm} \mathrm{H}_{2} \mathrm{O}$. These relationships were investigated by using linear regression analysis. The variables were compared between levels of PEEP by using parametric or non-parametric paired tests. We tested whether the values of rP15/P5 did significantly differ from 1 . The values of rP15/P5 were also compared across lung levels by using a linear model with mixed effects.

A $P$ value $<.05$ was taken as the statistical significance threshold. The statistical analysis was performed using statistics software (R 2.9.0, R Foundation for Statistical Computing, Vienna, Austria).

\section{Results}

\section{Characteristics of Subjects Included}

Fourteen subjects (11 men) with ALI $(n=2)$ or ARDS $(n=12)$ were included. Their median age was $68(65-$ 72) years, Simplified Acute Physiology Score II 48 (3850), height $175(170-178) \mathrm{cm}$, and ideal body weight 71 $(66-73) \mathrm{kg}$. Five subjects died during their ICU stay (ICU mortality $35 \%$ ). ALI/ARDS was investigated in the early stage (first week after ALI/ARDS onset), except for 2 subjects (median for the 14 subjects $3(2-3)$ d). Twelve cases resulted from a direct (primary) lung injury. $\mathrm{P}_{\mathrm{aO}_{2}}$ amounted to 79 (70-95) $\mathrm{mm} \mathrm{Hg}$ under $\mathrm{F}_{\mathrm{IO}_{2}} 0.50(0.50-$ 0.50), $\mathrm{P}_{\mathrm{aO}_{2}} / \mathrm{F}_{\mathrm{IO}_{2}} 169$ (144-191) $\mathrm{mm} \mathrm{Hg}$, tidal volume 420 (335-430) $\mathrm{mL}$, corresponding to $6(6-6) \mathrm{mL} / \mathrm{kg}$ ideal body weight, PEEP $8(8-10) \mathrm{cm} \mathrm{H}_{2} \mathrm{O}$, and breathing frequency 29 (25-32) breaths/min.

\section{Effects of PEEP on Respiratory Mechanic and Oxygenation}

The variables followed a normal distribution at each level of PEEP. As expected, PEEP ${ }_{t, r s}$ and $P_{\text {plat,rs }}$ were significantly greater at PEEP 15 than at PEEP 5 (see the Table). There was a trend to lower $\mathrm{C}_{\text {st.rs }}$ and $\mathrm{C}_{\mathrm{dyn}, \mathrm{rs}}$ at the $\mathrm{P}_{\text {plat,rs }}$, corresponding to higher PEEP level. Oxygenation

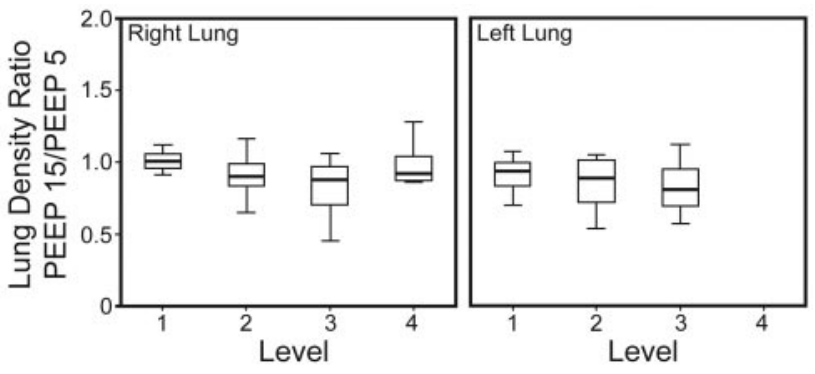

Fig. 2. Box-and-whiskers plots of lung density at PEEP $15 \mathrm{~cm} \mathrm{H}_{2} \mathrm{O}$ to lung density at PEEP $5 \mathrm{~cm} \mathrm{H}_{2} \mathrm{O}$ ratios (rP15/P5) across the lung levels according to Figure 1 for right and left lung. No significant difference was obtained across the lung levels for rP15/P5.

significantly improved at $\mathrm{P}_{\text {plat,rs }}$, corresponding to higher PEEP.

\section{Change in Density on Chest X-ray}

The intra-observer measurement error was $9.2 \%$. The intra-class correlation coefficient for intra-observer measurement of rP15/P5 ratios was 0.97 (95\% CI 0.96-0.98). The mean \pm SD size of the regions of interest was $3.45 \pm 1.57 \mathrm{~cm}^{2}$. The median value of $\mathrm{rP} 15 / \mathrm{P} 5$ in the 98 lung levels across the 14 subjects was $0.91(0.80-1.01)$, which was significantly different from $1(P<.001)$. There was no significant difference between lung levels regarding rP15/P5 (Fig. 2).

\section{Relationships Between Change in Density, Oxygenation, and Respiratory Mechanics}

The median values of $\mathrm{V}_{\text {rec }}$ and $\mu \mathrm{P} 15 / \mathrm{P} 5$ were 288 (173402) $\mathrm{mL}$ and $0.90(0.80-0.97)$, respectively. There was a significant negative correlation between $\mu \mathrm{P} 15 / \mathrm{P} 5$ and $\mathrm{V}_{\text {rec }}$ (Fig. 3): $\mathrm{V}_{\text {rec }}=1,412.1-1,230.3 \mu \mathrm{P} 15 / \mathrm{P} 5(\mathrm{R}=-0.77$, $P=.01)$. The reduction in $\mu \mathrm{P} 15 / \mathrm{P} 5$ tended to correlate with the increase in $\mathrm{C}_{\mathrm{dyn}, \mathrm{rs}}(\mathrm{R}=-0.49, P=.077)$ or in $\mathrm{P}_{\mathrm{aO}_{2}}(\mathrm{R}=-0.53, P=.05)$ between the $\mathrm{P}_{\text {plat,rs }}$ corresponding to PEEP $15 \mathrm{~cm} \mathrm{H}_{2} \mathrm{O}$ and the $\mathrm{P}_{\text {plat,rs }}$ corresponding to PEEP $5 \mathrm{~cm} \mathrm{H}_{2} \mathrm{O}$ (Fig. 4). There was no correlation between $\mu \mathrm{P} 15 / \mathrm{P} 5$ and change in $\mathrm{C}_{\mathrm{st}, \mathrm{rs}}$ (not shown).

\section{Discussion}

We found a significant correlation between the decrease in the $\mu \mathrm{P} 15 / \mathrm{P} 5$ ratio of density measured from the digital processed chest $\mathrm{X}$-ray and $\mathrm{V}_{\text {rec }}$ from the $\mathrm{P}_{\text {plat,rs }}$ corresponding to PEEP 5 to the $\mathrm{P}_{\text {plat,rs }}$ corresponding to PEEP $15 \mathrm{~cm} \mathrm{H}_{2} \mathrm{O}$.

\section{Study Limitations and Strengths}

Before discussing the present results, a critique of our methodology is required. The obvious major methodolog- 


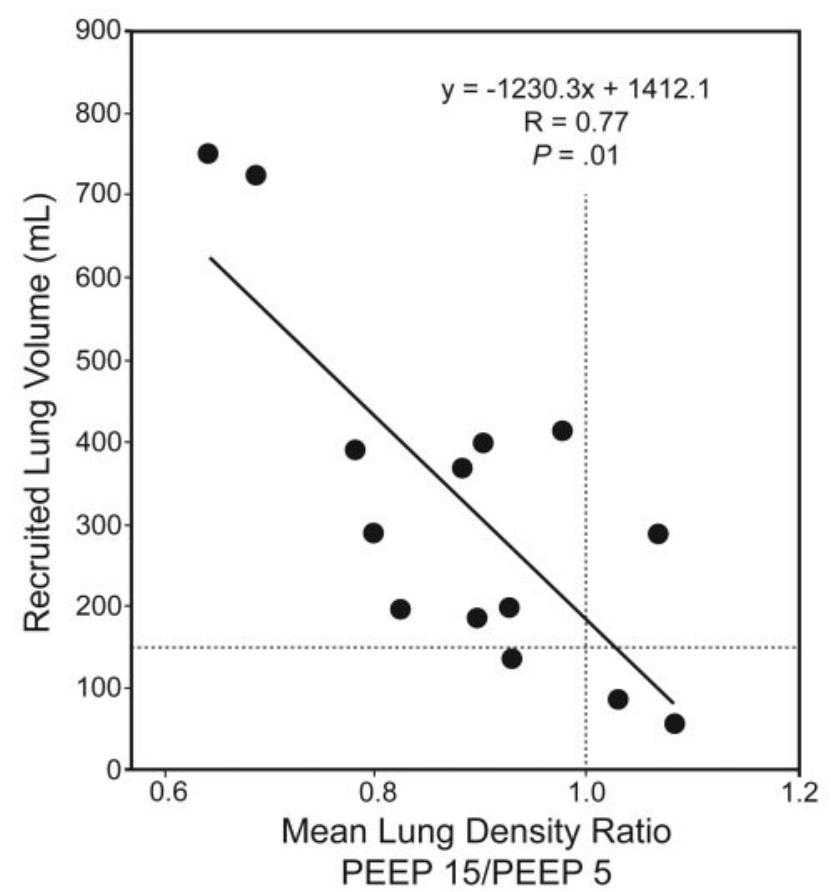

Fig. 3. Relationship between the recruited volume and the arithmetic mean of the ratios of lung density at PEEP $15 \mathrm{~cm} \mathrm{H}_{2} \mathrm{O}$ to lung density at PEEP $5 \mathrm{~cm} \mathrm{H}_{2} \mathrm{O}(\mu \mathrm{P} 15 / \mathrm{P} 5)$ over all regions of interest. The solid line is the regression line across the data points. The horizontal dotted line indicates the threshold to define recruiters (recruited volume above $150 \mathrm{~mL}$ ). The vertical dashed line is drawn from $\mu \mathrm{P} 15 / \mathrm{P} 5$ equal to 1 , indicating no change in lung density with the higher PEEP.

ical limitation is that frontal chest $\mathrm{x}$-ray cannot measure the density within a voxel in the same way as CT does. In a frontal chest $\mathrm{x}$-ray the anterior-to-posterior slices are merged, and this merging is not like a summation of planes that retain and create an average of the individual values of the density. We were well aware of this, and that is the reason why our main concern was to examine the change of density across different conditions of lung volume.

Second, the x-ray beams may cross devices used in the patient care, such as electrodes, vascular lines, gastric tubes, or endotracheal tubes that are then superimposed on the lung in the regions of interest and may jeopardize the analysis. Great care was taken to avoid this, and when it was not possible to remove them from the field of the beam, they were kept in the same position across the pictures. The way in which the regions of interest were drawn also helped to circumvent this problem.

Third, great care was also taken to standardize and keep constant the technical factors that can increase withinsubject variability. In addition to these measures, the device was kept in the same position in the subject's room; the body position of the subject in her/his bed was also kept constant, thanks to the measurement of the angle of the subject's trunk to the horizontal plane, of the distance
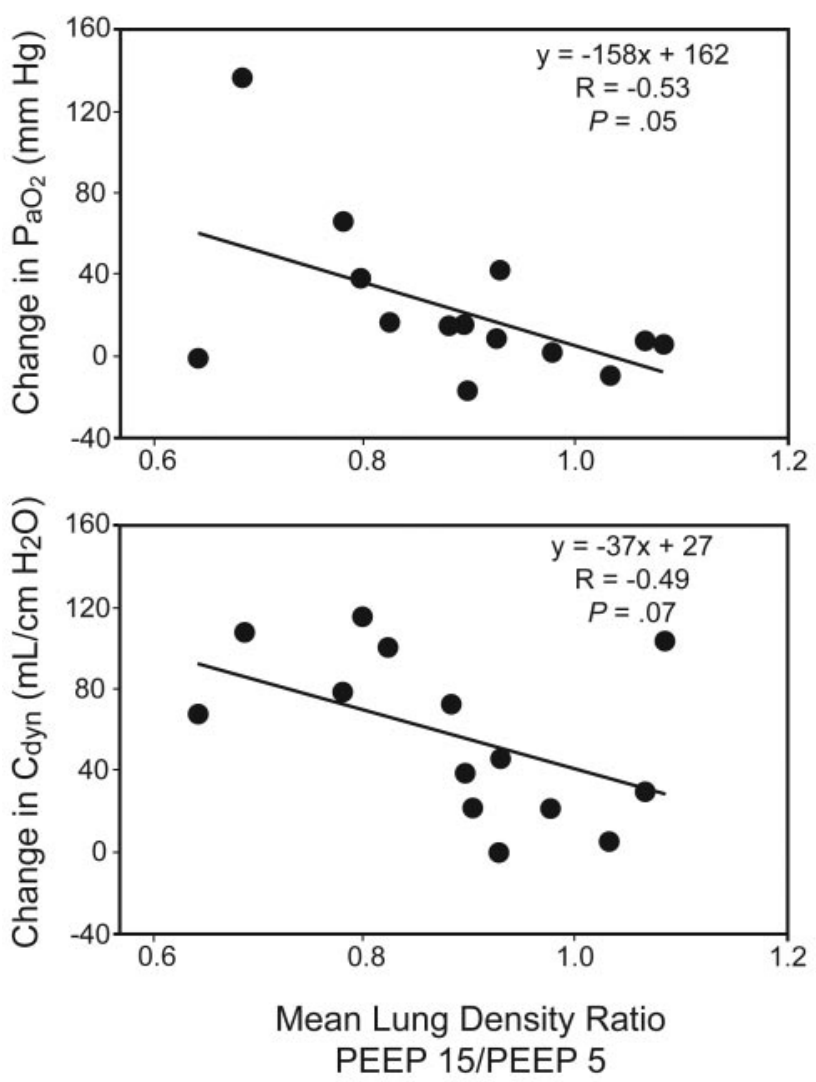

Fig. 4. Relationships of changes in $\mathrm{P}_{\mathrm{aO}_{2}}$ (upper panel) and in dynamic compliance of the respiratory system $\left(C_{d y n, r s}\right)$ (lower panel) to the arithmetic mean of the ratios of lung density at PEEP $15 \mathrm{~cm} \mathrm{H}_{2} \mathrm{O}$ to lung density at PEEP $5 \mathrm{~cm} \mathrm{H}_{2} \mathrm{O}$ over all regions of interest ( $\mu$ P15/P5) between PEEP $15 \mathrm{~cm} \mathrm{H}_{2} \mathrm{O}$ and PEEP $5 \mathrm{~cm} \mathrm{H} \mathrm{H}_{2} \mathrm{O}$. The lines are the regression lines.

between the source of the x-ray and the sternum of the subject, and the device settings.

Fourth, the different steps lasted a short time, with the advantage of minimizing the risk of bias, but hindering the exploration of short-term physiological findings. Fifth, the density measured has no unit. To circumvent this hindering of comparisons between subjects we used the ratio of both densities measured at the $\mathrm{P}_{\text {plat,rs }}$ corresponding to PEEP 15 and the $\mathrm{P}_{\text {plat,rs }}$ corresponding to PEEP 5. Sixth, we did not assess the inter-observer variability in chest $\mathrm{x}$-ray analysis. Finally, the technique was technically challenging, as it required 2 chest $\mathrm{x}$-rays taken under very carefully standardized conditions, at 2 different points in time, and a preliminary ultrasound study to rule out pleural effusion.

\section{Relationships Between Change in Density and $V_{\text {rec }}$}

We found that the rP15/P5 ratios were significantly lower than 1 , and that decrease in $\mu \mathrm{P} 15 / \mathrm{P} 5$ significantly corre- 
lated with $\mathrm{V}_{\text {rec }}$. We selected PEEP of $5 \mathrm{~cm} \mathrm{H}_{2} \mathrm{O}$ and $15 \mathrm{~cm} \mathrm{H}_{2} \mathrm{O}$ because they were those used by Gattinoni et al in their study assessing the lung recruitability by using the lung CT scan. ${ }^{5}$ This range allowed a clear distinction in $\mathrm{P}_{\text {plat,rs }}$ between PEEP levels (see the Table) and, hence, increased the likelihood for significant change in lung volume and aeration.

At least 2 reasons may explain why the rP15/P5 ratio was not significantly different across lung levels. First, the drawing of the regions of interest in the bottom of the lungs enclosed some parts of the diaphragm and heart, as suggested by the initial decline of rP15/P5 between lung levels 1 and 3, followed by its further increase from level 3 to 4 (see Fig. 2). Since this bias was expected, the extreme top and bottom parts of the lungs were discarded in the regions of interest selection, to optimize the delineation of intercostal spaces. We were also aware that the lowest part of the left lung delineation could be jeopardized by the left border of the heart, and therefore we did not draw a region of interest in the lower left lung.

Second, the change in density may not relate only to change in gas volume, but also to change in tissue fraction. In this case, the chest $\mathrm{x}$-ray cannot differentiate between gas fraction and tissue fraction. For example, it has been shown that PEEP redistributes the pulmonary blood flow toward dorsal and caudal lung regions in the supine position. ${ }^{14}$ In some instances in the present study the values of the P15/P5 ratios were greater than 1 . The role of perfusion redistribution may be accounted for in this finding. Furthermore, CT scan investigations in patients with ALI/ ARDS have provided negative values for alveolar recruitment, which are consistent with our present P15/P5 ratios greater than 1. For instance, Puybasset et $\mathrm{al}^{15}$ found that in the most caudal parts of the lungs, regional recruitment amounted to around $10 \mathrm{~mL}$. Gattinoni et al,, 5 investigating lung recruitability in ALI/ARDS patients, found loss of lung aeration and, hence, negative value of potential of recruitment, in 3 patients out of 68 .

According to Grasso et al, ${ }^{16}$ who defined recruiters and non-recruiters at the threshold of $\mathrm{V}_{\text {rec }} 150 \mathrm{~mL}$, only 3 of our subjects were non-recruiters, exhibiting $\mathrm{V}_{\text {rec }}$ lower than $150 \mathrm{~mL}$ (see Fig. 3). These subjects were investigated early in the course of ARDS. In 2 of them, with the lowest values of $\mathrm{V}_{\text {rec }}(56$ and $86 \mathrm{~mL})$, the $\mu \mathrm{P} 15 / \mathrm{P} 5$ ratio was greater than 1 , indicating increase in lung density with the higher PEEP.

The significant negative correlation between $\mathrm{V}_{\text {rec }}$ and change in $\mu \mathrm{P} 15 / \mathrm{P} 5$ might indicate true recruitment. ${ }^{17}$ The lack of a CT scan in our study precludes firm evidence because this finding may also represent overdistention. However, the fact that the reduction in $\mu \mathrm{P} 15 / \mathrm{P} 5$ was associated with a nearly significant increase in $\mathrm{C}_{\mathrm{dyn}, \mathrm{rs}}$ and in $\mathrm{P}_{\mathrm{aO}_{2}}$ suggests that the relationships of $\mu \mathrm{P} 15 / \mathrm{P} 5$ to $\mathrm{V}_{\text {rec }}$ may depict true recruitment. Should the increase in $\mu \mathrm{P} 15 / \mathrm{P} 5$ be associated with a decrease in $\mathrm{C}_{\mathrm{dyn}, \mathrm{rs}}$ and/or $\mathrm{P}_{\mathrm{aO}}$, the presence of overdistention would be more likely. Those subjects with an expected higher degree of overdistention (negative changes in $\mathrm{C}_{\mathrm{dyn}, \mathrm{rs}}$ in Fig. 4) are those with the smallest changes in $\mu \mathrm{P} 15 / \mathrm{P} 5$, indicating that this parameter might distinguish overdistention from recruitment.

Recently, in 42 mechanically ventilated patients the performance of chest x-ray to identify consolidation, interstitial syndrome, pneumothorax, and pleural effusion was assessed taking lung CT scan as the gold standard. ${ }^{18}$ The diagnostic accuracy of chest x-ray was $49,58,89$, and $59 \%$ for the corresponding radiological abnormalities. In this study, as in the early one by Rouby et al, ${ }^{19}$ the anatomical abnormalities were defined from the nomenclature committee of the Fleischner Society (ie, by eye). In the present study we attempted to improve the diagnostic performance of chest $\mathrm{x}$-ray using objective and quantitative analysis, for the first time, to the best of our knowledge. The present results should encourage further studies.

\section{Regional Approach of Lung Density From Digitalized Chest X-ray}

Chest $\mathrm{x}$-ray provides a picture of the whole lung and, hence, has the potential for a regional analysis of change in density, with the same limitations as mentioned above. Even though this was not the primary objective of the present study, we attempted to perform a regional analysis of rP15/P5 (see Fig. 2). The values of rP15/P5 were not found with statistically significant change across the lung levels by using a linear regression model. This lack of significance may be due to lack of power or to inappropriate use of a linear model. Indeed, discarding level 4 in the right lung resulted in a significant reduction in rP15/P5 from level 1 to level 3, irrespective of the lung side. Therefore, further studies are warranted.

\section{Conclusions}

In conclusion, digital chest $\mathrm{x}$-ray at the bedside of ARDS patients detected a significant reduction in lung density between the $\mathrm{P}_{\text {plat,rs }}$ corresponding to PEEP 15 and the $\mathrm{P}_{\text {plat,rs }}$ corresponding to PEEP $5 \mathrm{~cm} \mathrm{H}_{2} \mathrm{O}$, which correlated with $\mathrm{V}_{\text {rec }}$. It should be noted that the clinical applicability of the technique could be limited.

\section{REFERENCES}

1. Brower RG, Lanken PN, MacIntyre N, Matthay MA, Morris A, Ancukiewicz M, et al. Higher versus lower positive end-expiratory pressures in patients with the acute respiratory distress syndrome. N Engl J Med 2004;351(4):327-336.

2. Meade MO, Cook DJ, Guyatt GH, Slutsky AS, Arabi YM, Cooper DJ, et al. Ventilation strategy using low tidal volumes, recruitment maneuvers, and high positive end-expiratory pressure for acute lung 


\section{Evaluation of Recruited Lung Volume at Inspiratory Plateau Pressure With PeEP}

injury and acute respiratory distress syndrome: a randomized controlled trial. JAMA 2008;299(6):637-645.

3. Mercat A, Richard JC, Vielle B, Jaber S, Osman D, Diehl JL, et al. Positive end-expiratory pressure setting in adults with acute lung injury and acute respiratory distress syndrome: a randomized controlled trial. JAMA 2008;299(6):646-655.

4. Briel M, Meade M, Mercat A, Brower RG, Talmor D, Walter SD, et al. Higher vs lower positive end-expiratory pressure in patients with acute lung injury and acute respiratory distress syndrome: systematic review and meta-analysis. JAMA 2010;303(9):865-873.

5. Gattinoni L, Caironi P, Cressoni M, Chiumello D, Ranieri VM, Quintel $\mathrm{M}$, et al. Lung recruitment in patients with the acute respiratory distress syndrome. N Engl J Med 2006;354(17):17751786.

6. Costa EL, Borges JB, Melo A, Suarez-Sipmann F, Toufen C Jr, Bohm SH, et al. Bedside estimation of recruitable alveolar collapse and hyperdistension by electrical impedance tomography. Intensive Care Med 2009;35(6):1132-1137.

7. Arbelot C, Ferrari F, Bouhemad B, Rouby JJ. Lung ultrasound in acute respiratory distress syndrome and acute lung injury. Curr Opin Crit Care 2008;14(1):70-74.

8. Luecke T, Corradi F, Pelosi P. Lung imaging for titration of mechanical ventilation. Curr Opin Anaesthesiol 2012;25(2):131-140.

9. Eisenhuber E, Schaefer-Prokop CM, Prosch H, Schima W. Bedside chest radiography. Respir Care 2012;57(3):427-443.

10. Bernard GR, Artigas A, Brigham KL, Carlet J, Falke K, Hudson L, et al. The American-European Consensus Conference on ARDS. Definitions, mechanisms, relevant outcomes, and clinical trial coordination. Am J Respir Crit Care Med 1994;149(3):818-824.

11. Ranieri VM, Eissa NT, Corbeil C, Chasse M, Braidy J, Matar N, et al. Effects of positive end-expiratory pressure on alveolar recruitment and gas exchange in patients with the adult respiratory distress syndrome. Am Rev Respir Dis 1991;144(3):544-551.
12. Puech PA, L. B., Belfkih S, Lemaitre L, Douek P, Beuscart R. DicomWorks: software for reviewing DICOM studies and promoting low-cost teleradiology. J Digit Imaging 2007;20:122-130.

13. Bland JM, Altman DG. Statistical methods for assessing agreement between two methods of clincial measurement. Lancet 1986;1(8476): 307-310.

14. Richard JC, Bregeon F, Costes N, Bars DL, Tourvieille C, Lavenne $\mathrm{F}$, et al. Effects of prone position and positive end-expiratory pressure on lung perfusion and ventilation. Crit Care Med 2008;36(8): 2373-2380.

15. Puybasset L, Gusman P, Muller JC, Cluzel P, Coriat P, Rouby JJ. Regional distribution of gas and tissue in acute respiratory distress syndrome. III. Consequences for the effects of positive end-expiratory pressure. CT Scan ARDS Study Group. Adult Respiratory Distress Syndrome. Intensive Care Med 2000;26(9):1215-1227.

16. Grasso S, Fanelli V, Cafarelli A, Anaclerio R, Amabile M, Ancona $\mathrm{G}$, et al. Effects of high versus low positive end-expiratory pressures in acute respiratory distress syndrome. Am J Respir Crit Care Med 2005;171(9): 1002-1008.

17. Vieira SR, Puybasset L, Richecoeur J, Lu Q, Cluzel P, Gusman PB, et al. A lung computed tomographic assessment of positive endexpiratory pressure-induced lung overdistension. Am J Respir Crit Care Med 1998;158(5):1571-1577.

18. Xirouchaki N, Magkanas E, Vaporidi K, Kondili E, Plataki M, Patrianakos A, et al. Lung ultrasound in critically ill patients: comparison with bedside chest radiography. Intensive Care Med 2011;37(9): 1488-1493.

19. Rouby JJ, Puybasset L, Cluzel P, Richecoeur J, Lu Q, Grenier P. Regional distribution of gas and tissue in acute respiratory distress syndrome. II. Physiological correlations and definition of an ARDS Severity Score. CT Scan ARDS Study Group. Intensive Care Med 2000;26(8):1046-1056.

This article is approved for Continuing Respiratory Care Education credit. For information and to obtain your CRCE

(free to AARC members) visit www.rcjournal.com 